\title{
Taro Leaf Blight (Phytophthora colocasiae) Disease Pathogenicity on Selected Taro (Colocasiae esculenta) Accessions in Maseno, Kenya
}

\author{
Carren Adhiambo Otieno \\ Department of Biological Sciences, School of Science, Rongo University, Rongo, Kenya \\ Email: caadhiambo@rongovarsity.ac.ke, joycarotieno@gmail.com
}

How to cite this paper: Otieno, C.A. (2020) Taro Leaf Blight (Phytophthora colocasiae) Disease Pathogenicity on Selected Taro (Colocasiae esculenta) Accessions in Maseno, Kenya. Open Access Library Journal, 7: e6393.

https://doi.org/10.4236/oalib.1106393

Received: May 3, 2020

Accepted: June 5, 2020

Published: June 8, 2020

Copyright $\odot 2020$ by author(s) and Open Access Library Inc.

This work is licensed under the Creative Commons Attribution International License (CC BY 4.0).

http://creativecommons.org/licenses/by/4.0/

\section{(c) (i) Open Access}

\begin{abstract}
Taro (Colocasia esculenta) is an important staple crop for small-scale farmers in Asia, Pacific, Americas and Africa. Taro corms and leaves are sources of important nutrients such as calcium, phosphorus, iron, vitamin $\mathrm{C}$, thiamine, riboflavin and niacin. Its cultivation is under threat from many diseases. Taro leaf blight (TLB), a major threat to taro production is caused by the fungus Phytophthora colocasiae Racib. Its control has relied on the use of fungicides which are too expensive for the majority of farmers. The study on virulence of various strains of TLB isolates in Western Kenya has been unknown but is a necessary inclusion in the management of the disease. This study aimed at evaluating the incidence and severity of TLB-disease on inoculated accessions with a view of determining the variability of the isolates' virulence and the accessions' TLB disease incidence and severity. Eight taro accession from Kenya and eight from Pacific-Caribbean were inoculated using four TLB strains (21R1, 21R2, 3R1 and 3R2) in greenhouse condition. A Complete Randomized Design was used with each accession replicated three times. The data included: the total number of leaves, leaf area, incidence and severity of the disease. The data obtained was analyzed using ANOVA at $95 \%$ confidence level to determine TLB disease incidence and severity. Analysis of Variance and the means declared significant were separated by the least significant difference at $5 \%$. The two categories of isolates caused TLB disease lesions, on inoculated leaves. However, higher incidence and severity were caused by isolates $21 \mathrm{R} 1$ and $21 \mathrm{R} 2$ than isolates $3 R 1$ and 3R2. On inoculation with 3R1 pathogen isolate, $39.01 \%$ and $88.18 \%$ incidence were recorded on Pacific-Caribbean and Kenyan taro respectively. On inoculation with pathogen isolate $21 \mathrm{R} 1$ a $\%$ incidence of $47.22 \%$
\end{abstract}


and $88.18 \%$ was recorded on Pacific-Caribbean and Kenyan taro respectively. The control did not show significant disease incidence in all taro accessions. The mean TLB disease incidence for the Pacific-Caribbean accessions was $20.08 \%$ and that of Kenya was $59.04 \%$. The lowest TLB disease incidence among the Kenyan taro of $34.4 \%$ was recorded from KNY/KAK/16 of Kakamega. The highest incidence among the Pacific-Caribbean of $32.48 \%$ was obtained from CE/IND/01 of Indonesia. Similar results were obtained with disease severity. Higher disease tolerance was realized among the Pacific-Caribbean accessions. The knowledge obtained from this research would help in the development of taro cultivars with improved resistance to taro leaf blight pathogen. This will increase taro production in Kakamega county of Kenya.

\section{Subject Areas}

Mycology

\section{Keywords}

Green House, Incidence, Severity, Taro Accessions, Pathogenicity

\section{Introduction}

Taro (Colocasia esculenta) is a perennial tropical starchy root crop, which belongs to the Araceae family. It originated from South East Asia and later spread into other parts of the continent and Africa. Taro grows best under hot and wet conditions with temperatures above $21^{\circ} \mathrm{C}$. It is sensitive to frost therefore a lowland crop [1]. Taro has both medicinal and nutritional uses. It is food for man and animals [2]. The corms and leaves are the major parts consumed in different parts of the world. The corms, have high carbohydrate content and can be eaten in many forms: roasted, boiled, fried, baked and pounded while the leaves are eaten as preferred vegetable, representing an important source of vitamins which include: vitamin A, vitamin B, vitamin C, folate, thiamine and riboflavin. It is also rich in proteins, sugars and minerals such as calcium, manganese, phosphorus, potassium and zinc [3]. It is known to reduce tuberculosis, ulcers, pulmonary congestion and fungal infection [4].

The production of taro in Kenya in recent times, has been affected by taro leaf blight caused by Phytophthora colocasiae which has also been reported to have threatened the sustainability of taro production globally [5]. The impact of the blight in Kenya has led to continued loss of taro and its genetic resources. Kenya has experienced decreasing food security as a result of smallholder farmers and improper disease control and prevention [6]. The agricultural diversification and promotion of underutilized crops is the alternative way to address food security and alleviating poverty amongst rural folks.

Taro Leaf Blight is caused by the oomycete Phytophthora colocasiae, one of the most economically significant diseases with a capacity to reduce yield of $25 \%$ 
to $95 \%$ in taro-growing countries [7]. The disease affects all parts of the crop including the leaves, corms, petioles and cormels, resulting in extensive damage of the foliage [8]. Most primary infections of hosts initiated by Phytophthora species originate from soilborne inoculum. The pathogen may survive in soil in the absence of a host as mycelia, zoospore cysts, sporangia, chlamydospores or oospores. Soil survival of $P$. colocasiae sporangia has been reported to persist for fewer than 21 days in naturally infested soil [9]. Oospores as the survival structure of homothallic Phytophthora species in soil are well established. However, oospores of heterothallic species in naturally infested soil are rare. There is inadequate information with respect to the pathogenicity of the disease across the growing counties of Kenya. However, to effectively develop a sustainable management tool for the disease, there is the need to assess the extent of pathogenicity of taro leaf blight disease isolates. The present study therefore seeks to assess the pathogenicity of the disease in selected taro accessions from Kenyan and $\mathrm{Pa}$ cific-Caribbean taro and their corresponding disease incidence and severity.

Non-conventional and ecologically friendly approach for plant protection could minimize the scope of chemical control, thus contributing to the development of sustainable agriculture. This research work has sought to determine the incidence and severity of Phytophthora colocasiae in Pacific-Caribbean and Kenya taro accessions through conducting greenhouse pathogenicity test. The baseline information on the incidence and severity of the disease in Kenya will foster a strategic planning towards its management [10].

\section{Materials and Methods}

\subsection{Location and Experimental Sites}

The study was carried out in the field, laboratory and greenhouse at Maseno University, Kenya. Maseno University is located along Kisumu-Busia highway. It lies within Latitude: $0^{\circ} 00^{\prime} 60.00^{\prime \prime} \mathrm{N}$ and Longitude: $34^{\circ} 35^{\prime} 59.99^{\prime \prime} \mathrm{E}$ and 1503 metres above sea level.

\subsection{Cultivation of Pacific-Caribbean and Kenyan Taro under Field Conditions}

Experimental area measuring $1120 \mathrm{~m}^{2}(70 \mathrm{~m}$ by $50 \mathrm{~m}$ ) not previously cultivated was cleared using a machete, hand ploughed and harrowed twice using jembes and hoes before planting. Soil was made into raised beds in preparation for planting. A total of sixteen taro accessions obtained from both Pacific-Caribbean and Kenya included: BL/HW/08 BL/HW/26, BL/SM/80, BL/SM/92, CA/JP/03, CE/IND/1, CE/THA/07, $\mathrm{CE} / \mathrm{THA} / 24, \mathrm{KNY} / \mathrm{BSA} / 41, \mathrm{KNY} / \mathrm{CNT} / 33, \mathrm{KNY} / \mathrm{KAK} / 16$, $\mathrm{KNY/KSM/81,} \mathrm{KNY/KTL/61,} \mathrm{KNY/MU/75,} \mathrm{KNY/SYA/50,} \mathrm{KNY/SYA/51.} \mathrm{The}$ taro suckers were planted in $60 \mathrm{~cm}$ deep holes and each sucker firmly placed using hands according to the methods of [11]. The spacing was $0.5 \mathrm{~m}$ between plants and $1.0 \mathrm{~m}$ between rows. Watering was done in the morning and evening for one month approximately one liter per plant using a sprinkler. The plants were ar- 
ranged in a completely randomized design (CRD) since there were no control experiments in the field. The design also ensured that each individual plant had the same chance of becoming a participant in the study. The plants were allowed to grow for two months before being transferred to pots in greenhouse.

\subsection{Isolation and Identification of Phytophthora colocasiae Isolates}

Infected taro leaves with lesions of TLB blight were collected from the field at Kitale-Kenya taro growing regions: Moisbridge, Mailsaba, Bikeke and Kiminini. The leaves were preserved in separate plastic bags and transported to Maseno University laboratory. The leaves were cut with razor blade in to small fragments of $2 \mathrm{~mm}$ from the advancing edges of the disease and surface-sterilized in 5\% diluted solution of sodium hypochlorite for 30 seconds and rinsed in three successive changes of sterile distilled water for 3 minutes. The leaf fragments were dried on sterilized filter paper and four fragments placed on solidified cool PDA medium in each Petri dish. These dishes were labeled and put in an incubator at room temperature of $22^{\circ} \mathrm{C}-26^{\circ} \mathrm{C}$ according to the methods of [12]. After 2 - 3 days, extensive mycelia formed around the leaf fragment was aseptically collected and sub-cultured in Petri dishes containing freshly prepared PDA medium. They were then covered with cover slips. The cultures were incubated for 4 days maintaining them at room temperature in a drawer within the laboratory according to the methods of [13]. The remaining isolates were then stored at room temperature in $2 \mathrm{ml}$ tubes containing 3 - 4 plugs of mycelium, 3- and 1-ml water for future use.

\subsection{Pathogenicity Test of Isolates}

To verify the ability of the pathogen to cause taro leaf blight disease, a pathogenicity test was performed on 3 weeks-old disease-free taro plants grown in pots under greenhouse conditions. A suspension of 106 conidia/ml was sprayed on taro leaves using a hand-sprayer compressor until run-off. Control plants were sprayed with sterilized water only. Plants were covered with polythene bags to create a relative humidity of about $100 \%$, and incubated for 48 hours at $20^{\circ} \mathrm{C} \pm$ $2^{\circ} \mathrm{C}$. Following removal of plastic bags, the plants were observed every 24 hours for the development of symptoms. The pathogenic nature of the isolates was determined by proving Koch's postulates through pathogenicity test according to the methods of [14]. After two days, the inoculated sites showed water soaking lesions at the beginning but later turned brown according to the observations of [15]. Severe disease symptoms occurred 4 days after inoculation. Blighted leaves generally turned yellowish at the advance stage of the disease. Disease spread along the midrib with whitish mycelial patches seen on the blighted area. At the advance stages of the infection, leaves curled and the apex dried-off. The affected area amounted to $40 \%-70 \%$ of the total leaf surface. The pathogen was re-isolated after confirming the Koch's postulates. 


\subsection{Inoculum Preparation}

Two Phytophthora colocasiae pathogen isolate treatments coded 21R1 and 3R1 showing low growth and very fast growth respectively were selected for greenhouse inoculation as they had distinctively pure cultures of the pathogen. Spore suspension was prepared from 21 days old culture of different isolates, by flooding the surface of the growing colonies in each Petri-dish with $5 \mathrm{ml}$ of sterile distilled water and dislodging the spores with a small brush. The suspension was centrifuged for 3 minutes and the supernatant was filtered through a 2 layered sterile muslin cheesed cloth. A drop of spore suspension was placed on the haemocytometer chamber, covered with a slide. Mycelia mat from the culture were harvested using sterile scalpel into an electric blender. After blending for five minutes, $200 \mathrm{ml}$ of sterile distilled water was added into $500 \mathrm{ml}$ conical flask and filtered using double layer muslin cloth according to the methods of [16]. Distilled water was used on the leaves as control.

\subsection{Soil Sterilization for Greenhouse Use}

Black sandy loamy soil from Maseno botanical garden was sifted to remove stones, plastic materials and plant debris. The soil was steam sterilized in a barrel at $100^{\circ} \mathrm{C}$ for two hours. The sterilized soil was left in the barrel overnight to cool before use according to the methods of [17]. Pacific-Caribbean and Kenyan taro plants earlier planted on soil not previously cultivated included: KNY/SYA/51, KNY/KAK/16, CA/JP/O3, CE/THA/07, KNY/BSA/41, BL/HW/26, BL/SM/80, $\mathrm{KNY} / \mathrm{SYA} / 50$, KNY/KTL/61, and BL/SM/92, KNY/MU/75, KNY/CNT/33, BL/HW/08, CE/THA/24, KNY/KSM/81, KNY/SYA/50.

Ten-liter plastic buckets filled with the sterilized top soil and the samples placed at $1 \mathrm{~m} \times 1 \mathrm{~m}$ using a complete randomized design for the treatments, however, the control experiment was blocked to prevent contamination. The experiment had three replications. The crops were watered with 2 litres per plant in the morning, every two days using clean water and administered at the base of the crop. The tubers were covered with the soil and firmed down according to the methods of [16].

\subsection{Plant Inoculation}

Soil inoculation was done by pouring $20 \mathrm{ml}$ of inoculums suspension at the base of the stem of each plant according to the methods of [16]. This was done three months after planting. Control seedlings were treated with the same quantity of sterile distilled water. Both the inoculated and the control seedlings were covered with polythene bags to increase humidity around the plants according to the methods of [16]. After 24 hours, polythene bags were removed for 20 minutes and the plants watered. Four days after inoculation, the polythene bags were finally removed. There were 16 accession with 2 plants per accession per treatment. There were two pathogen inoculation treatments and one control. The greenhouse experiment data was collected for 5 months. 


\subsection{Virulence and Pathogenicity Test of Phytophthora colocasiae under Greenhouse Conditions}

Eight Pacific-Caribbean accessions of taro, CA/JP/O3, CE/THA/07, BL/HW/26, BL/SM/80, BL/HW/08, CE/THA/24, BL/SM/92 CE/IND/01 and eight Kenyan taro accessions KNY/SYA/51, KNY/KAK/16, KNY/BSA/41, KNY/SYA/50, $\mathrm{KNY} / \mathrm{KTL} / 61, \mathrm{KNY} / \mathrm{MU} / 75, \mathrm{KNY} / \mathrm{CNT} / 33, \mathrm{KNY} / \mathrm{KSM} / 81$ were transplanted in plastic pots filled with sterilized soils in a greenhouse. These plants were arranged in a complete randomized design with four replicates of four plants per replicate. The taro was inoculated 60 days after planting. Spore suspension of $P$. colocasiae isolates which were adjusted with a haemocytometer to a spore density of $3 \times$ 104 spores/ml of distilled water. Inoculation was done by using a syringe to inject the spore suspension on three spots on the leaves. Observations were carried out and lesion diameter was measured using a ruler. Data for average lesion diameter, tissue collapse and defoliation was recorded for 14 days.

\subsection{Determination of Mean Number of Leaves}

The total numbers of leaves were obtained through physical counting and the mean number of leaves obtained by dividing the total number of leaves by the total number of a particular taro accession. The results were recorded at monthly intervals from the appearance of the first symptom (a week after inoculation) till the crop was harvested. New partially furled leaves and old leaves touching the ground were not evaluated. Taro leaf blight disease symptoms included; yellow and red liquid drops in the middle of the lesion with dry solid, brown particles on leaf lamina often with white ring of sporangia around the edge of lesions, which later become papery and would fall out producing "shot hole" appearance.

\subsection{Determination of Disease Incidence of $P$. colocasiae}

Percentage incidence was calculated using the formula:

Percentage (\%) disease incidence

$$
=\frac{\text { Number of leaves affected per accession }}{\text { Total number of leaves sampled per accession }} \times 100
$$

The accessions were evaluated on a $0-100 \%$ incidence of taro leaf blight.

\subsection{Determination of Disease Severity}

Areas of leaves were measured by using non-destructive methods of [18] using the formula $W_{P} \times L_{P A}$ where

$W_{P}=$ Leaf width passing the petiole attaching point;

$L_{P A}=$ Length of the petiole attaching point to the apex of leaf.

Areas of leaves infected by the disease were assessed using the maximum length and breadth of the affected leaf area. The measurements were obtained by use of a transparent ruler.

Disease severity ratings per accession per experiment were undertaken using a subjective score scale of 1 - 9 adopted from [19] (Table 1). However, records were made as the percentage leaf area infected. 
Table 1. Subjective score scale of 1 - 9 for computation of disease severity.

\begin{tabular}{ccc}
\hline Scale & \% leaf area infected & Description \\
\hline $0-1$ & 0 & no infection \\
$1-2$ & 3 & $>1 \%$ but $<10 \%$ \\
$2-3$ & 10 & $11-20$ small lesions \\
$3-4$ & 25 & $10 \%$ leaf area infected \\
$4-5$ & 50 & $25 \%$ leaf area infected \\
$5-6$ & 75 & $50 \%$ leaf area infected \\
$6-7$ & 90 & $75 \%$ leaf area infected \\
$7-8$ & 97 & Only few green areas left (much less than $10 \%)$ \\
$8-9$ & 100 & foliage completely destroyed/dead
\end{tabular}

The score was repeated monthly for five months. The start of scoring took into consideration the beginning of disease development i.e. first appearance of TLB symptoms on taro leaves.

\section{Results}

\subsection{Mean Number of Leaves of Pacific-Caribbean and Kenyan Taro In-Vitro}

The result on Table 2 on mean monthly number of leaves of Pacific-Caribbean and Kenyan taro showed that the highest number of leaves of 5.5 was at age seven, the last month of study. The lowest mean number of leaves of 3.4 occurred at age three which was also the first month of data recording. The accession with significantly $(\mathrm{p}<0.05)$ highest mean number of leaves of 4.7 was Pacific-Caribbean Hawaiian accession BL/HW/26 and the one with the lowest of 4.2 was Kenyan Kakamega accession KNY/KAK/16. Pacific-Caribbean and Kenyan taro were statistically the same in terms of number of leaves. Pacific-Caribbean taro accessions recording an average of 4.48 and Kenyan accessions 4.45 leaves.

Figure 1 below showed that the number of leaves of Pacific-Caribbean and Kenyan taro had a steady but slow increase in number of leaves from month three to month seven. The error bars indicated significant difference in number of leaves only between age three in September and age seven in January. At age four to six, numbers of leaves were statistically the same.

\subsection{Taro Leaf Blight Disease Incidence of Pacific-Caribbean and Kenyan Taro}

The result of Pacific-Caribbean and Kenyan taro disease incidence was as shown in Figure 2. Region of taro origin, the accessions and age portrayed statistically significant $(\mathrm{p}<0.001)$ effect on TLB disease incidence. Interactions between age and region also significantly $(\mathrm{p}<0.001)$ influenced TLB disease incidence. 
Table 2. Mean number of leaves compared between Pacific-Caribbean and Kenyan taro accessions.

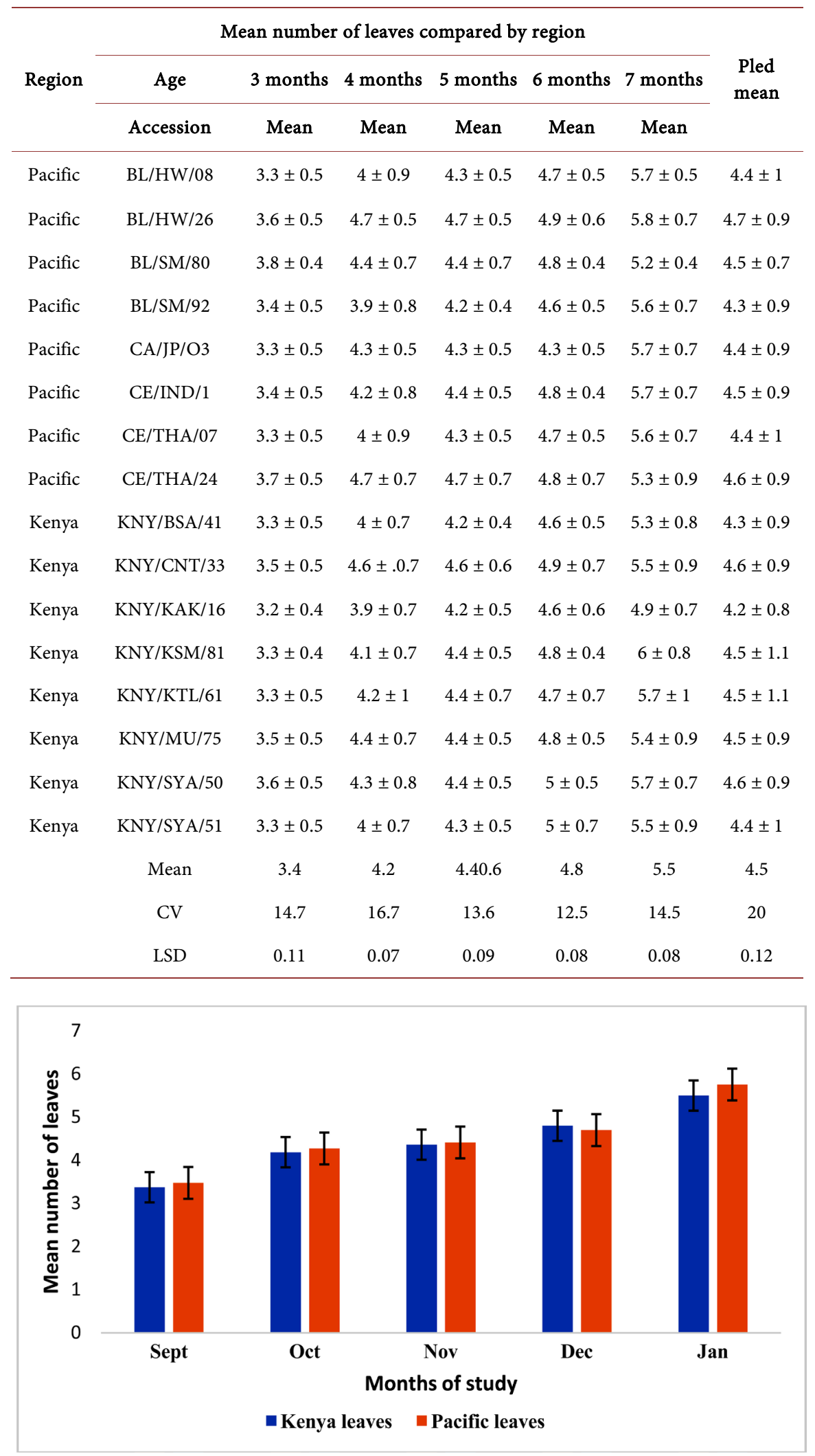

Figure 1. Comparison of number of leaves of Pacific-Caribbean and Kenyan taro. 


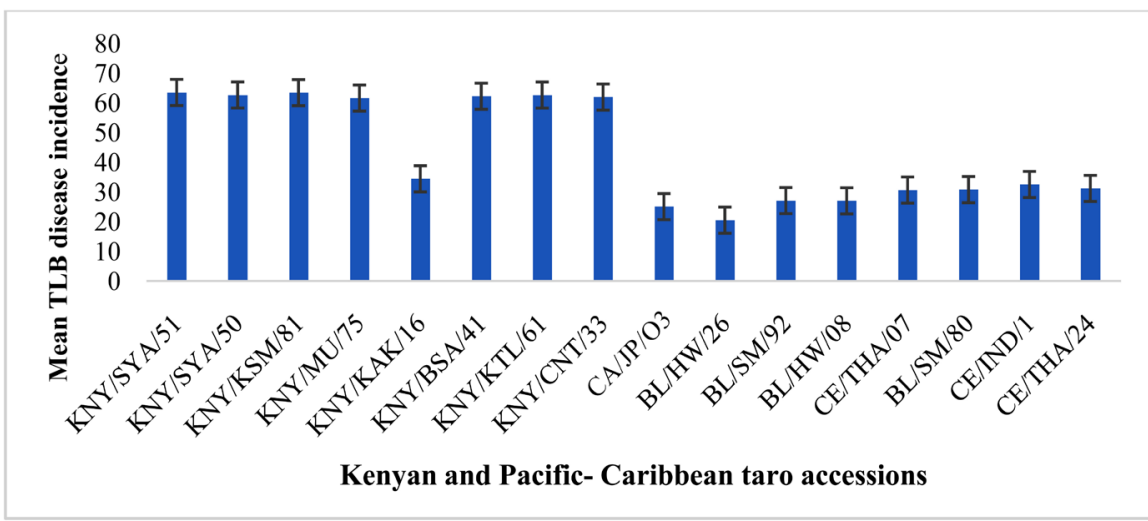

Figure 2. Mean TLB disease incidence of Kenyan and Pacific-Caribbean taro under greenhouse study.

All the Pacific-Caribbean taro accessions recorded a decrease in TLB disease incidence between 6 - 7 months. All the Kenyan taro accessions showed regular increase in TLB disease incidence except KNY/KTL/61 from Kitale that decreased, increased and eventually decreased. The mean disease incidence for the Pacific-Caribbean accession was $20.08 \%$ and that of Kenya was $59.04 \%$.

The highest disease incidence of $63.47 \%$ was recorded from Kenyan accession KNY/SYA/51 and the lowest of 20.49\% from Pacific-Caribbean accession $\mathrm{BL} / \mathrm{HW} / 26$. The highest incidence among the Pacific-Caribbean of $32.48 \%$ was obtained from CE/IND/01 of Indonesia. The lowest TLB disease incidence among the Kenyan taro of $34.4 \%$ was recorded from KNY/KAK/16 of Kakamega. This indicated that the lowest incidence among the Kenyan accessions was significantly $(\mathrm{p}<0.05)$ higher than the highest TLB disease incidence among the Pacific-Caribbean accessions (Figure 2). No Pacific-Caribbean taro accession recorded above $30 \%$ disease incidence.

All the accessions showed incidence right from three months of age. The highest mean incidence of $47.18 \%$ was obtained at age 5 months and the least of $38.38 \%$ at age three. The incidence rate appeared almost constant between age five and seven (Figure 3).

\subsection{Effect of 21R1 and 3R1 TLB Disease Isolates' Innoculation on Disease Incidence upon Kenyan and Pacific-Caribbean Taro Accessions}

Taro leaf blight lesion development on both the Kenyan and Pacific-Caribbean taro begun four days after inoculation. The percentage disease incidence was generally high for the inoculated plants, ranging from $39 \%$ to $88.18 \%$ (Figure 4 ). The disease incidence showed significant $(\mathrm{p}<0.05)$ differences on inoculation with the two isolates. Isolate 3R1 generally recorded slightly higher disease incidence $(88.18 \%)$ than isolate 21R1 (86.15\%). Isolate 21R1 however recorded higher percentage disease incidence (47.217\%) than 3R1 (37.24\%) on Pacific-Caribbean taro. The control plants showed very minimal disease incidence ranging from $0 \%$ to $0.33 \%$. 


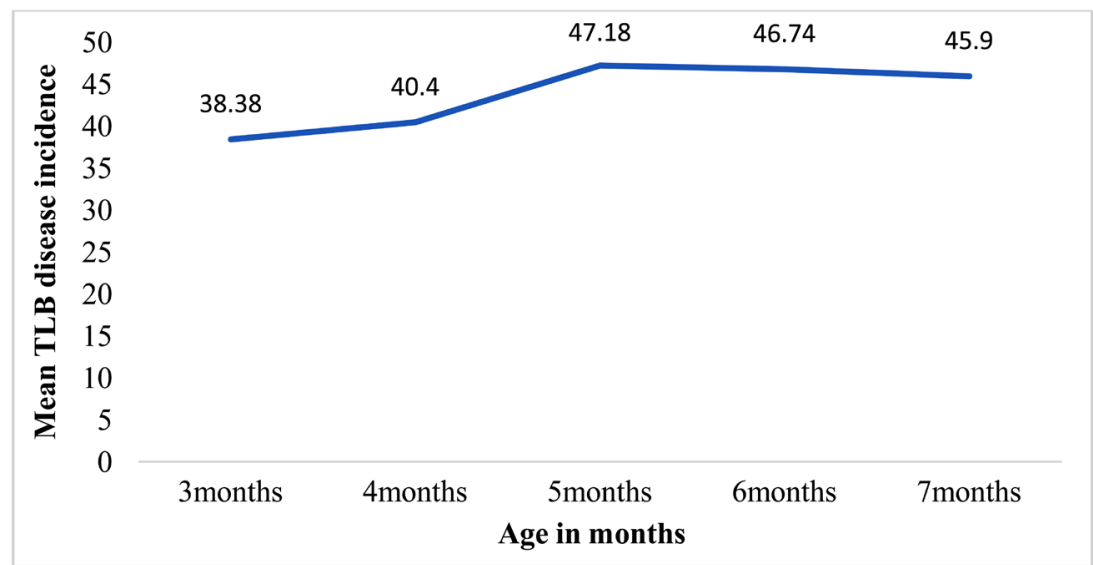

Figure 3. Mean TLB disease incidence of Pacific-Caribbean and Kenyan taro vis age under greenhouse study.

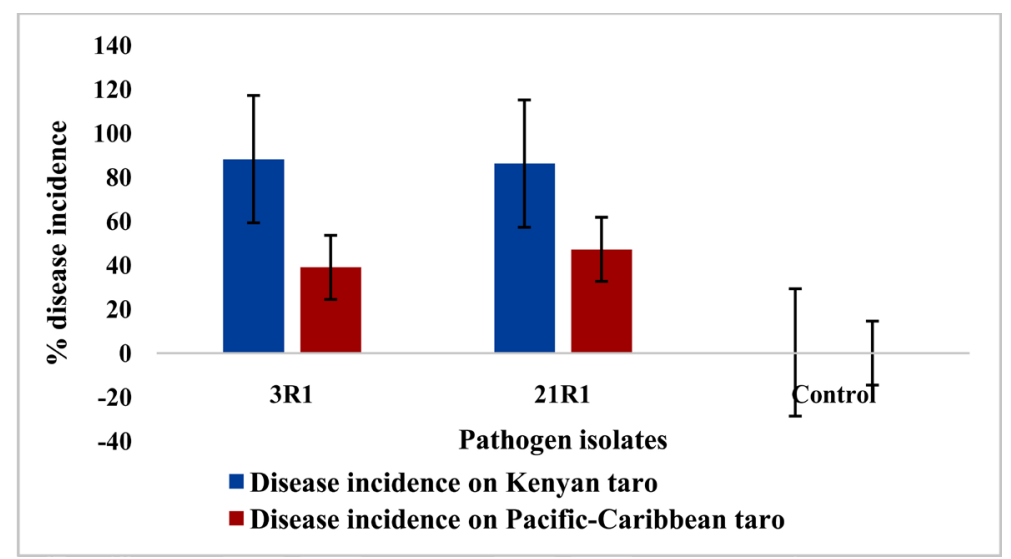

Figure 4. Effect of 21R1 and 3R1 TLB disease isolates on disease incidence upon Kenyan and Pacific-Caribbean taro accessions.

\subsection{Taro Leaf Blight Disease Severity of Pacific-Caribbean and Kenyan Taro In-Vitro}

The result on taro leaf blight disease severity on Pacific-Caribbean greenhouse taro was as indicated on Figure 5 below. Independently, region, accession and age significantly $(\mathrm{p}<0.05)$ influenced TLB disease severity. Similarly, the interaction between region of origin and age showed significant $(\mathrm{p}<0.001)$ effects on disease severity. Further, interactions between accessions and age significantly $(\mathrm{p}<0.001)$ affected disease severity which steadily increased from third month to seventh month in both Pacific-Caribbean and Kenyan taro (Figure 5). Pacific-Caribbean accession $\mathrm{BL} / \mathrm{SM} / 80$ maintained a severity of $30.56 \%$ between age five and six months, an indication of tolerance to TLB disease. The mean TLB disease severity for the Pacific-Caribbean taro was $20.47 \%$ and that of Kenya was $29.64 \%$.

Most Kenyan taro accessions recorded higher TLB disease severity than the Pacific-Caribbean taro. Kenyan aaccession KNY/BSA/41 scored significantly ( $p$ $<0.05$ ) the highest blight disease severity of $43.56 \%$ and the lowest severity of 9.36\% was recorded with Pacific-Caribbean accession BL/HW/26.

There was gradual increase in disease severity with age of taro plant (Figure 6). 


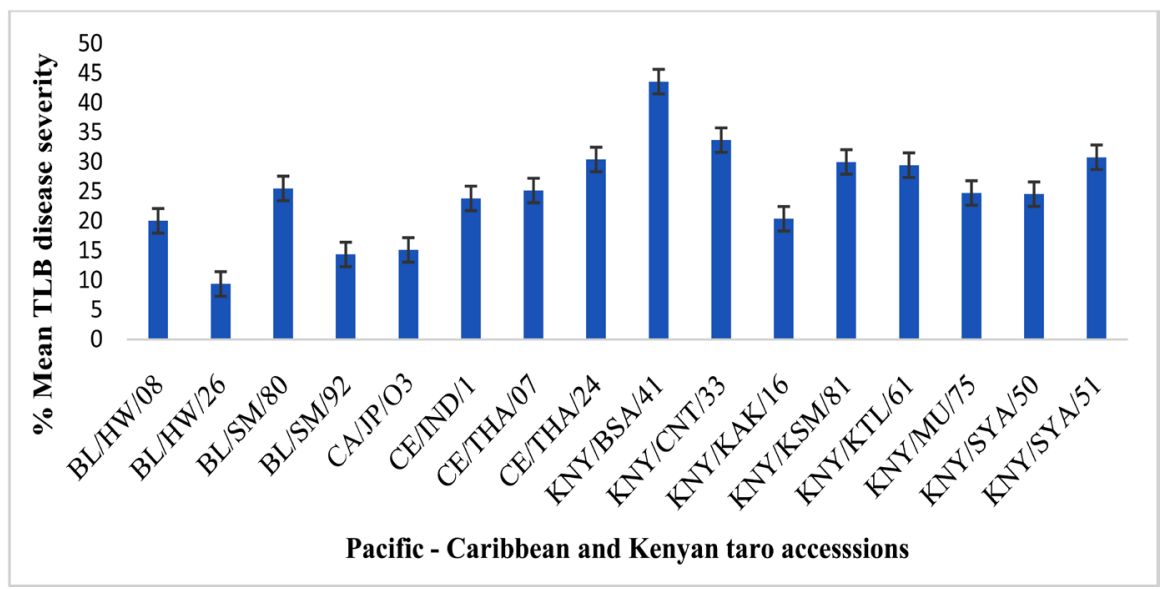

Figure 5. Mean TLB disease severity of Pacific-Caribbean and Kenyan taro under greenhouse study.

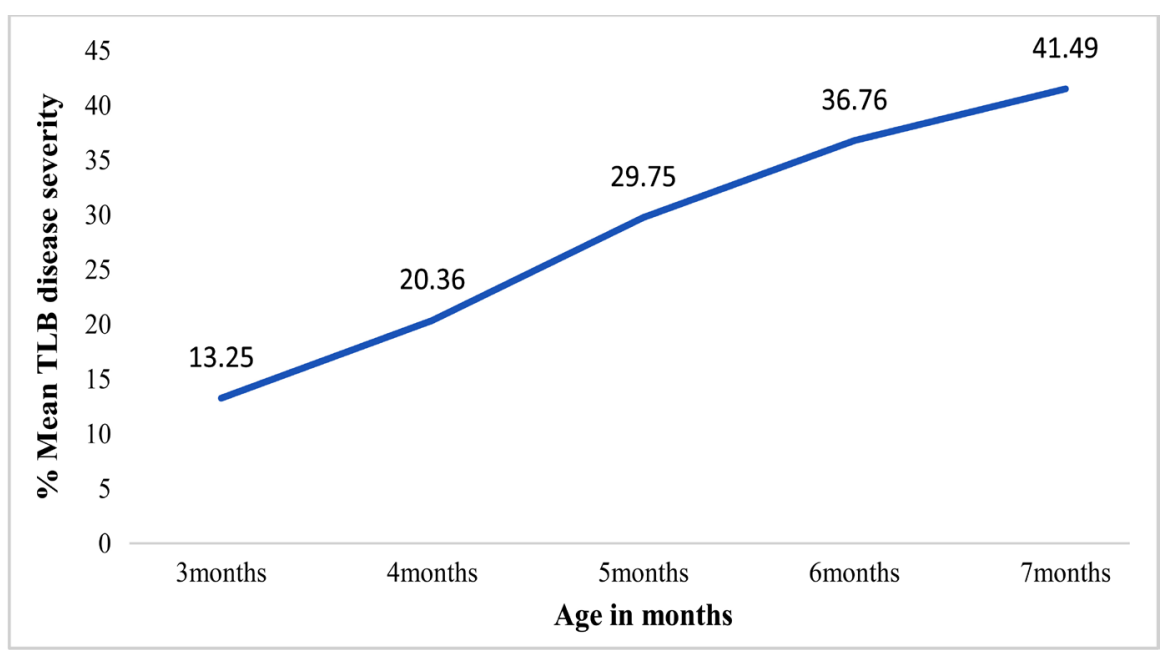

Figure 6. Mean TLB disease severity of Pacific-Caribbean and Kenyan taro vis age under greenhouse study.

The highest severity was recorded at age seven months with $41.49 \%$ and the lowest at age two months with $13.25 \%$.

There was no significant $(\mathrm{p}<0.05)$ difference in the effect of 21R1, 21R2, 31R1 and 3R2 TLB disease isolates on disease severity upon Kenyan and Pacific-Caribbean taro accessions.

\section{Discussion}

\subsection{Mean Number of Pacific-Caribbean and Kenyan Taro Leaves In-Vitro}

The number of leaves seemed to increase with age of plant. The numbers of leaves of Pacific-Caribbean and Kenyan taro were statistically the same. Those of Pacific-Caribbean taro accessions recorded an average of 4.48 and Kenyan accessions 4.45 leaves. This could have been due to the fact that greenhouse was controlled and very minimal environmental effects were realized. 


\subsection{Taro Leaf Blight Disease Incidence of Pacific-Caribbean and Kenyan Taro In-Vitro}

The lower disease incidence in Pacific-Caribbean taro could be due to genetic properties developed by the accessions to reduce the effect of the pathogen. This could have been attributed to the tendency of the plant getting rid of infected leaves due to hypersensitivity reaction. This study was in concurrence with the findings of [20] that TLB disease incidence increased gradually later became stable. It was also in tandem with the findings of [21] that decrease in disease incidence could be brought about by growth and flashes of new leaves which were not attached by the pathogen due to the plant gaining tolerance as a result of increased immunity.

Age seven which was the last month of data collection registered significantly $(\mathrm{p}<0.05)$ low mean disease incidence. This indicated that the pathogen slowly progressed from initial stages of growth and then decreased in incidence with age. This study disagreed with that of [20] that age of plant affected the extent of disease susceptibility and that susceptibility increased with age of plant. The Pacific-Caribbean taro disease incidence increased from age three to five then started decreasing from age five to seven which was indicative of disease tolerance.

\subsection{TLB Disease Inoculation Effect on Disease Incidence upon Kenyan and Pacific-Caribbean Taro Accessions In-Vitro}

Studies on virulence and pathogenicity of Phythopthora colocasiae on the different taro accessions indicated that the two isolates caused lesions on inoculated leaves with variable pathogenicity. This was consistent with a previous study by [22] who stated that virulence tests showed a significant difference $(\mathrm{p}<0.05)$ in the rate of infection on the green house plants thought to be attributed to their differences in morphology.

There was a gradual increase in lesion as days increased except in a few taro accessions. Invasion of taro leaves by the TLB isolates resulted in severe or slight disease development, depending on the accession and isolate. The leaves had spots which were water soaked with dry gray appearance. The spots increased in size, coalesced and quickly destroyed the leaves. This concurred with the reports of [23] that the lower leaf surface of TLB infected plants, had water soaked spots which were dry and gray. The finding also suggested that the pathogen colonized and damaged the plant tissue at an early stage.

\subsection{Taro Leaf Blight Disease Severity of Pacific-Caribbean and Kenyan Taro In-Vitro}

Kenyan accessions had generally higher disease severity than the Pacific-Caribbean taro revealing that different locations from which taro were obtained influenced TLB disease severity. This was consistent with the report of [24] that improved Samoan accession BL/SM/132 from Pacific-Caribbean neither showed tissue collapse even after TLB pathogen inoculation nor symptom of taro leaf blight disease compared to other taro accessions which showed high severity rates. 
Differences in disease severity were also portrayed among the different Pacific-Caribbean and Kenyan taro accessions. This could be attributed to genetic and environmental differences as described by [10]. [25] Attributed the differences in disease severity to genetic differences among taro plants. [26] Reported in support of this finding that there was a differential degree of response against taro leaf blight disease among different taro accessions. The result showed increase in TLB disease severity with increase in age as described by [26] that late growing periods of taro revealed higher TLB disease levels than early periods. In the TLB-Kenya pathosystem, there was evidence of physiological adaptation of Phytophthora Colocasiae. This finding was also in concurrence with the report of [27] that the role of pathogen variability and adaptation could not be precluded and may account for the observations.

\section{Conclusion}

The results obtained on taro leaf blight disease inoculation on different taro accessions revealed that both isolate strains caused lesions, on inoculated leaves. Isolate $21 \mathrm{R} 1$ and $21 \mathrm{R} 2$ showed stronger sensitivity to leaf infection irrespective of accession tested although not statistically different from 3R1 isolate. There was variability in pathogenicity based on low TLB disease incidence and severity in some taro accessions which included Pacific-Caribbean BL/HW/26, BL/SM/80, CA/JP/03 and Kenyan KNY/KAK/16. Pacific-Caribbean accessions showed minimal symptoms of $P$. colocasiae and therefore most of them were termed resistant to Phytophthora colocasiae as compared to Kenyan accessions which showed high incidence and severity thus were susceptible to the disease. As such, germplasm from Kakamega should be included in taro improvement programs to ensure use of high resistant taro accessions in Kenya.

\section{Acknowledgements}

The author wishes to acknowledge the support of Maseno University Botany department staff for availing the land, laboratory and greenhouse and for technical support that made this research a success. I would like to express our appreciation to taro farmers of Kenya and the Pacific-Caribbean for their cooperation in providing the germplasm samples.

\section{Conflicts of Interest}

The author declares no conflicts of interest regarding the publication of this paper.

\section{References}

[1] Rao, R., Hunter, D., Eyzaguirre, P. and Matthews, P. (2010) Ethnobotany and Global Diversity of Taro. In: Rao, V.R., Matthews, P.J., Ezyaguire, P.B. and Hunter, D., Eds., The Global Diversity of Taro: Ethnobotany and Conservation, Bioversity International, Rome, Italy, 2-5. 
[2] Rochani, A. (1994) The Role of Taro (Colocasia esculenta) in Live Hood of Local People in the Ayanna Sub-District Sorong Iran Jaya Province. The Second Taro Symposium, Manokwari, Indonesia, 23-24 November 1994, 105-109.

[3] FAOSTAT (2010) Food and Agriculture Organization of United Nations.

[4] Joshua, S.A. (2010) Identification of the Major Foliar Fungal Disease of Colocasia esculenta (L.) Schott and Its Management in the Kumasi Metropolis, Kwame Nkrumah University of Science and Technology. Msc Thesis.

[5] Deo, P.C., Anand, P.T., Taylor, M., Becker, D.K. and Harding, R.M. (2009) Improving Taro (Colocasia esculenta var. esculenta) Production Using Biotechnological Approaches. South Pacific Journal of Natural Sciences, 27, 6-13. https://doi.org/10.1071/SP09002

[6] Akwee, P.E., Netondo, G., Kataka, J.A. and Palapala, V.A. (2015) A Critical Review of the Role of Taro Colocasiae esculenta L. (Schott) to Food Security: A Comparative Analysis of Kenya and Pacific Island Taro Germplasm. Scientia Agricola, 9, 101-108. https://doi.org/10.15192/PSCP.SA.2015.9.2.101108

[7] Sharma, K., Mishra, A.K. and Misra, R.S. (2008) Analysis of AFLP Variation of Taro Population and Markers Associated with Leaf Blight Resistance Gene. Academic Journal of Plant Sciences, 1, 42-48.

[8] Gadre, U.A. and Joshi, M.S. (2003) Influence of Weather Factors on the Incidence of Leaf Blight of Colocasiae. Annuals of Plant Protection Sciences, 11, 168-170.

[9] Gollifer, D.E. and Brown, J.F. (1974) Phytophthora Leaf Blight of Colocasiae esculenta in the British Solomon Islands. Papua New Guinea Agricultural Journal, 25, 6-11.

[10] Omege, T.E., Ugwuoke, K.I., Adinde, J.O., Ogwulumba, S.I. and Unigwe, L.O. (2016) Effect of Cropping Season on the Control of Taro Leaf Blight (Phytophthora colocasiae) of Cocoyam (Colocasiae esculenta C.) in Nsukka, South Eastern Nigeria. International Journal of Advanced Biological Research, 6, 30-39.

[11] Brunt, J., Hunter, D. and Delp, C. (2001) A Bibliography of Taro Leaf Blight. Secretariat of the Pacific Community, Noumea, $93 \mathrm{p}$.

[12] Shrestha, S.K. (2012) Investigation of Phytophthora Species: Phytophthora colocasiae on Taro and Phytophthora Recovered from Streams in Eastern Tennessee. A Thesis Presented for the Master of Science Degree, University of Tennessee, Knoxville, 1-57.

[13] Adomako, J., Kwoseh, C.K., Moses, E. and Larbi-Koranteng, S. (2016) Prevalence of Phytophthora Leaf Blight of Taro (Colocasiae esculenta (L.) Schott) in the Semi Deciduous Forest Zone of Ghana. American Journal of Experimental Agriculture, 11, 1-7. https://doi.org/10.9734/AJEA/2016/23806

[14] Lin, M.J. and Ko, W.H. (2008) Occurrence of Isolates of Phytophthora colocasiae in Taiwan with Homothallic Behaviour and Its Significance. Mycologia, 100, 727-734. https://doi.org/10.3852/08-070

[15] Manza, W.S., Zarafi, A.B. and Alabi, O. (2008) Incidence of Leaf Blight Caused by Fusarium pallidoroseum on Varied Age of Caster (Ricinus communis) Inoculated Using Different Methods. African Journal of General Agriculture, 4, 1-5.

[16] Asraku, J.S. (2010) Identification of the Major Foliar Fungal Disease of Colocasiae esculenta (L.) Schott and Its Management in the Kumasi Metropolis. MSC Thesis, Kwame Nkrumah University of Science, Kumasi, 1-68.

[17] Chan, L.F., Lu, C.T., Lu, H.Y. and Lai, C.H. (1993) A Simple Method for Estimating Leaf Area in Wetland Taro (Colocasiae esculenta (L.) Schott). Journal of Agricultural Research, China, 42, 162-172. 
[18] Harlapur, S.I. (2005) Epidemiology and Management of Turcicum Leaf Blight of Maize Caused by Exserohilum turcicum. PhD Thesis, The University of Agricultural Sciences, Dharwad.

[19] Simongo, D.K., Gonsales, I.C. and Mesangkei (2016) North Philippine Root Crop Research and Training Center, Benguet State University, La Trinidad, Benguet 2601. International Journal of advancement in Research and Technology, 5, 6.

[20] Chowdhury, M.S.M. and Hossain, I. (2011) Effects of Temperature, Rainfall and Relative Humidity on Leaf Spot of Jackfruit Seedling and Its Eco-Friendly Management. A Scientific Journal of Krishi Foundation, 9, 126-136. https://doi.org/10.3329/agric.v9i1-2.9487

[21] Nath, V.S., Basheer, S., Jeeva, M.L. and Veena, S.S. (2016) Genetic and Phenotypic Characterization of Phytophthora colocasiae in Taro Growing Areas of India. Journal of Plant Pathology \& Microbiology, 7, 383. https://doi.org/10.4172/2157-7471.1000383

[22] Mbong, G.A., Fokunang, C.N., Lum, A., Fontem, Bambot, M.B. and Tembe, E.A. (2013) An Overview of Phytophthora colocasiae of Cocoyams: A Potential Economic Disease of Food Security in Cameroon. Discourse Journal of Agriculture and Food Sciences, 1, 140-145.

[23] Charles, F., Grace, M., Evelyn, M., Estella, T. and Hanna, R. (2016) Screen House and Field Resistance of Taro Cultivars to Taro Leaf Blight Disease (Phytophthora colocasiae). British Biotechnology Journal, 15, 1-5. https://doi.org/10.9734/BBJ/2016/14317

[24] Miyasaka, S.C., McCulloch, C.O. and Nelson, S.C. (2012) Taro Germplasm Evaluated for Resistance to Taro Leaf Blight. HortTechnology, 22, 838-849. https://doi.org/10.21273/HORTTECH.22.6.838

[25] Nath, V.S., Senthil, M., Hedge, V.M., Jeeva, M.L., Misra, S.R., Veena, S.S. and Raj, M. (2013) Molecular Evidence Supports Hyper Variability in Phytophthora colocasiae Associated with Leaf Blight of Taro. European Journal of Plant Pathology, 136, 483-494.

[26] Shakywar, R.C., Pathak, S.P., Pathak, M., Tomar, K.S. and Singh, H. (2013) Developmental Behavior of Leaf Blight of Taro Caused by Phytophthora colocasiae. Vegetos, 26, 167-170. https://doi.org/10.1007/s10658-013-0181-z

[27] Ramathani, I. (2009) Characterization of Turcicum Blight Epidemics and Pathogen Population in the Exserohilum turcicum-Sorghum Pathosystem in Uganda. MSc Thesis, Makerere University Kampala, Kampala, 25.

https://doi.org/10.5958/j.2229-4473.26.1.024 